\title{
Global citizenship education, identities, and values: New insights and perspectives
}

\author{
Simona Popa ${ }^{1}$
}

Published online: 23 July 2020

(C) UNESCO IBE 2020

I am pleased to introduce this general issue, which brings together leading scholars to reflect on critical topics ranging from global citizenship education (GCE) and values and ethics, to citizen identity and the role that textbooks can play in peacebuilding. These topics are more relevant than ever. The main thrust of several articles in this issue concerns issues of interpretation of a field that is still trying to find its feet. Refreshingly free from the usual limited, and typically Western-centric and neoliberal, conceptions of GCE, these articles make a remarkable attempt to expand the definition of GCE and to think through its long-term possibilities. They spell out a conviction that GCE can be "an essential tool to not only build understanding across borders and cultures but to advance our social, political, economic, and environmental interconnectedness necessary to address global and local issues" (Torres and Bosio 2020).

Running through all the articles in this issue is that same kind of acute moral sensibility, collective self-questioning, and sometimes uncomfortable truth-telling. These are all essential for a deeper understanding of the field and the challenges brought about by globalization- "as the most profound dynamic of this historical moment, a development realized on many different levels and spaces of human and natural existence" (Torres and Bosio 2020).

The article by Carlos Alberto Torres and Emiliano Bosio, "Global citizenship education at the crossroads: Globalization, global commons, common good, and critical consciousness", presents itself as a symposium in the true sense of the word: conversational in style, stimulating and provocative, and drawing together the threads into a final conclusion about what it means to educate for critical global citizenry in an increasingly multicultural world. This article-dialogue addresses current criticisms of global citizenship and challenges frequent misinterpretations of GCE. It starts by considering the phenomenon of globalization and the UN Global Education First Initiative, which aims to further global citizenship and to highlight the relationship between GCE, global peace, global commons, and the common good. Building on the assumption that GCE should be about learners' emancipation

Simona Popa

ibe.prospects@unesco.org

1 UNESCO International Bureau of Education, P.O. Box 199, 1211 Geneva, Switzerland 
toward critical consciousness, the dialogue concludes by drawing a parallel between the "mission" of GCE in contemporary educational institutions and Paulo Freire's notion of critical consciousness.

In his article, "Understanding and promoting ethics and values education: The methodological challenge", Manzoor Ahmed looks at two studies recently undertaken to examine how schools promote Sustainable Development Goals (SDG) Target 4.7—including ethics and values. UNESCO's Mahatma Gandhi Institute of International Education for Peace and Sustainable Development (MGIEP) in Delhi examined to what extent concepts and competencies related to Target 4.7 have been mainstreamed in education policies and curricula in 22 countries across Asia. Education Watch, a civil-society group in Bangladesh that monitors progress in pre-tertiary education in the country, took the promotion of ethics and values through school education as the subject for its 2017 report. This article describes the methodological concerns and how the MGIEP comparative study and the Bangladesh study address those concerns. The SDG agenda, particularly Target 4.7, constitutes a frame of reference for both studies. The article discusses the relevance of SDG Goal 4 and Target 4.7 for the two studies and briefly presents the objectives, the methodology, and the nature of conclusions derived from those studies. Next, it takes a comparative view of the two studies' methodologies and analyses. Finally, the conclusion points to implications for further research and policy discourse.

In her article, "Through a girl's eyes: Social ontologies of citizen identity among Jordanian and refugee students in Jordan's double-shift secondary schools", Patricia K. Kubow examines the social ontological perspectives of 92 young female students through an analysis of their views on citizen identity and the citizenship discourse promoted in three all-girl double-shift secondary schools in Amman. Jordan, after Turkey and Lebanon, has one of the highest populations of Syrian refugees in the world. To address the issue of overcrowding in schools, a double-shift system operates, whereby Jordanian students receive schooling in the morning and Syrian and other refugee students in the afternoon. The young women's ontologies are informed by a complex set of identity markers: namely, nationality, religion, culture, ethnicity (Arabness), gender, and developmental stage (youth). The study reveals that youth ontological security is rooted in Arab heritage, Islamic identity, and the state's emphasis on preservation of peace over student reactions to contemporary political crises in the Middle East. This empirically grounded, qualitative scholarship serves as a call for more youth studies on citizen identity in the Arab world.

In their article, "Transnationalism and the International Baccalaureate Learner Profile", Fazal Rizvi, Glenn C. Savage, John Quay, Daniela Acquaro, Richard J. T. Sallis, and Nima Sobhani examine the ways in which the International Baccalaureate's Learner Profile is interpreted and enacted in three different national settings. Using the data collected from a comparative study of the Learner Profile in nine International Baccalaureate schools in India, Hong Kong, and Australia, the authors question the widely held belief that understandings of the key attributes of the Learner Profile are nationally inflected. They suggest, instead, that these schools relate to their localities in a range of complex and multifaceted ways, and that the differences between individual schools within the same country are often more significant than differences between nations when it comes to putting the Learner Profile into practice. The authors introduce the idea of "transnational learning spaces" to describe a range of common features across these schools, including highly culturally diverse and globally mobile student populations and a shared disposition toward cosmopolitanism.

In their article, "Language education in the EU and the US: Paradoxes and parallels", Jill V. Jeffery and Catherine van Beuningen present a cross-continental examination of the 
wide variation that exists with regard to how policymakers address the challenges of providing language education. They argue that across the globe, linguistically heterogeneous populations increasingly define school systems at the same time that developing the ability to communicate cross-culturally is becoming essential for internationalized economies. While these trends seem complimentary, they often appear in paradoxical opposition, as represented in the content and execution of nationwide education policies. Their analysis reveals parallel tensions among aims for integrating immigrant populations, closing historic achievement gaps, fostering intercultural understanding, and developing multilingual competences. To consider implications of such paradoxes and parallels in policy foundations, the authors compare language education in the US and in the EU (focusing on the Netherlands as an illustrative case study).

In their article, "South Sudanese primary school textbooks: Transforming and reinforcing conflict", Catherine Vanner, Thursica Kovinthan Levi, and Spogmai Akseer argue that not only can primary-school textbooks provide space for learning about peace and inclusion, they can also reinforce messages of inequality and division. Their thematic analysis of South Sudan's textbooks for pupils in Grade 4 Social Studies, English, and Christian Religious Education uses a conceptual framework that positions education as having multiple potential overlapping roles in relation to conflict-victim, accomplice, and transformer-to show that while the textbooks' content does contain some motions toward social change, it more often passively reinforces the status quo. While peace and social acceptance of diversity and gender equality are sometimes explicitly promoted, there is an overarching emphasis on maintaining and accepting social norms without critically interrogating the social structures that can foster inequality and lead to conflict. This analysis positions the textbooks primarily as accomplices to conflict, with some movement toward transformation, across the themes of religion and ethnicity, governance, gender, and conflict.

Seungah S. Lee, in her article, "Fostering 'global citizens'? Trends in global awareness, agency, and competence in textbooks worldwide, 1950-2011", asks how various aspects of GCE have been present in textbooks cross-nationally over time. Based on a longitudinal dataset of over 600 social-science textbooks from around the world, she argues that textbooks have increasingly incorporated global awareness, global agency, and skills to recognize multiple perspectives. Her findings further suggest that what it means to be a "citizen" has expanded beyond national boundaries, such that individuals are increasingly viewed as global agents, able to contribute to and make a difference not only for their local community but also for global ones. This view is especially adopted in textbooks from countries that are democratic and embedded in the international community.

I hope the articles in this issue will rekindle new interest in GCE, values, and identities. Even if they invite no easy answers, we must learn once again how to pose the questions.

Simona Popa

\section{References}

Torres, C. A., \& Bosio, E. (2020). Global citizenship education at the crossroads: Globalization, global commons, common good, and critical consciousness. Prospects. https://doi.org/10.1007/s11125-01909458-w.

Publisher's Note Springer Nature remains neutral with regard to jurisdictional claims in published maps and institutional affiliations. 